\title{
Bioenergy technologies in long-run climate change mitigation: results from the EMF-33 study
}

\section{Vassilis Daioglou, et al. [full author details at the end of the article]}

Received: 15 October 2018 / Accepted: 15 July 2020/Published online: 24 August 2020

(C) The Author(s) 2020

\begin{abstract}
Bioenergy is expected to play an important role in long-run climate change mitigation strategies as highlighted by many integrated assessment model (IAM) scenarios. These scenarios, however, also show a very wide range of results, with uncertainty about bioenergy conversion technology deployment and biomass feedstock supply. To date, the underlying differences in model assumptions and parameters for the range of results have not been conveyed. Here we explore the models and results of the 33rd study of the Stanford Energy Modeling Forum to elucidate and explore bioenergy technology specifications and constraints that underlie projected bioenergy outcomes. We first develop and report consistent bioenergy technology characterizations and modeling details. We evaluate the bioenergy technology specifications through a series of analyses-comparison with the literature, model intercomparison, and an assessment of bioenergy technology projected deployments. We find that bioenergy technology coverage and characterization varies substantially across models, spanning different conversion routes, carbon capture and storage opportunities, and technology deployment constraints. Still, the range of technology specification assumptions is largely in line with bottom-up engineering estimates. We then find that variation in bioenergy deployment across models cannot be understood from technology costs alone. Important additional determinants include biomass feedstock costs, the availability and costs of alternative mitigation options in and across end-uses, the availability of carbon dioxide removal possibilities, the speed with which large scale changes in the makeup of energy conversion facilities and integration can take place, and the relative demand for different energy services.
\end{abstract}

Keywords Bioenergy $\cdot$ Biomass $\cdot$ Climate policy $\cdot$ Technological change $\cdot$ Scenario analysis Integrated assessment models

This article is part of the special issue "Assessing Large-scale Global Bioenergy Deployment for Managing Climate Change (EMF-33)” edited by Steven Rose, John Weyant, Nico Bauer, Shinichiro Fuminori, Petr Havlik, Alexander Popp, Detlef van Vuuren, and Marshall Wise.

Electronic supplementary material The online version of this article (https://doi.org/10.1007/s10584-02002799-y) contains supplementary material, which is available to authorized users. 


\section{Introduction}

Studies have highlighted that bioenergy could play a potentially significant role in the long-run management of climate change, substantially lowering the cost of realizing climate goals, and even facilitating the feasibility of those goals (Rose et al. 2014; Clarke et al. 2014; Luckow et al. 2010; Klein et al. 2014; Kriegler et al. 2014; Van Vuuren et al. 2010). Many of these same studies have also indicated significant variation in results, illustrating that bioenergy's potential role is highly uncertain regarding bioenergy conversion technology deployment and biomass feedstock supply. These general findings are investigated in greater detail in this 33rd study of the Stanford Energy Modeling Forum (EMF-33), which focuses explicitly on evaluating the potential role of bioenergy technologies in pursing ambitious climate objectives (Bauer et al. 2018; Rose et al. 2020). Figure 1 provides an illustration of the magnitude and heterogeneity of bioenergy deployment for a given climate policy and set of technology assumptions from the EMF-33 study.

There is understandable skepticism about the feasibility of large-scale bioenergy deployment. Concerns have been raised regarding the implications of the volume of biomass potentially needed, as well as the characteristics and deployment levels of bioenergy facilities over time (Anderson and Peters 2016; Buck 2016; Field and Mach 2017; Fuss et al. 2014; Bui et al. 2018; Lomax et al. 2015; Creutzig et al. 2015; Smith et al. 2016). To date, underlying differences in bioenergy modeling methodologies and assumptions have not been conveyed or explored. The EMF-33 study was designed explicitly to address this need and inform thinking about the viability of bioenergy for climate management. While Bauer et al. (2018) gives an overview on bioenergy deployment scenarios and a broad sensitivity analysis, and Rose et al. (2020) provides an overview on biomass supply modeling, this paper elucidates and explores bioenergy technology specifications and constraints that underlie projected bioenergy outcomes.

Transparency on details of bioenergy technology assumptions is needed to facilitate interpretation and evaluation of results, to inform R\&D strategies, and to inform policy
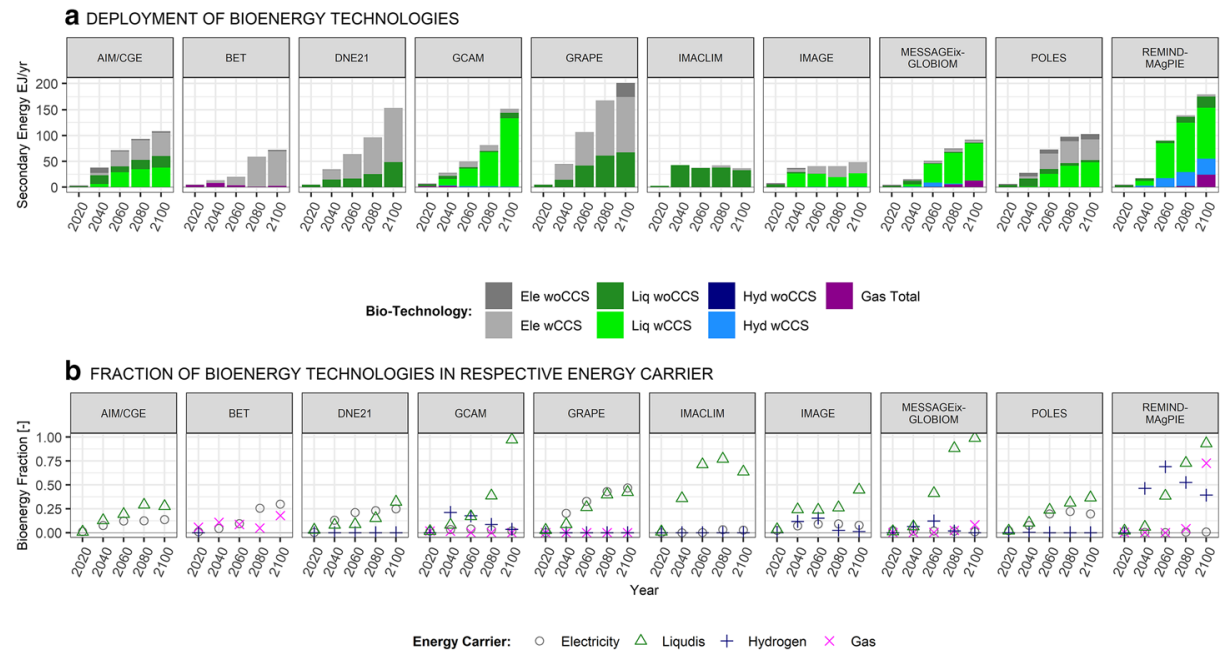

Fig. 1 Deployment of bioenergy by model for a climate scenario with a $1000 \mathrm{GtCO}_{2}$ carbon budget for energy and industrial $\mathrm{CO}_{2}$ emissions over the period 2011-2100 - a annual deployment (EJ/year) and b bioenergy as a fraction of total of respective secondary energy carrier 
aspirations and design. Projected cost-effective deployment patterns of bioenergy for containing climate change depend on assumptions regarding the availability, cost, and performance of bioenergy conversion technologies, as well as implementation barriers, technology transition assumptions, and system-wide limitations. This paper provides transparency and analysis, the former by elucidating the representations and parameterizations of bioenergy technologies, and the latter in the evaluation of those representations and scenario deployment results. We systematically present and compare assumptions concerning bioenergy technologies and the bioenergy deployment and transition dynamics emerging from the integrated assessment models (IAMs) participating in the EMF-33 study. This systematic comparison contributes to improved transparency and understanding of the uncertainty around future bioenergy technology performance and deployment, and offers insights into the bioenergy strategies observed in long-run climate management scenarios.

The study is organized as follows: first, we describe our approach, then, we present results as a progression of assessments from parameters to deployment. Specifically, we assess bioenergy technology cost parameters, bioenergy technology cost (including feedstock and $\mathrm{CO}_{2}$ capture costs), and bioenergy technology deployment. We conclude with a summary of key insights and further discussion.

\section{Methods}

The overall EMF-33 intermodel comparison study is motivated by the need to understand the feasibility of climate change mitigation targets and uncertainty about the role and deployment of advanced bioenergy technologies (ABT). The EMF-33 scenarios assume limits on global carbon budgets, applied to cumulative global energy and industry $\mathrm{CO}_{2}$ emissions from 2011 to 2100 (see Bauer et al. 2018). Each model participating in the EMF-33 study achieves the carbon budget by imposing a constraint on cumulative emissions, setting a global emissions trajectory that satisfies the cumulative constraint, or setting a global $\mathrm{CO}_{2}$ price path that achieves the budget. The socioeconomic context of these scenarios is similar across models with SSP2-like assumptions that locate models in the medium range of challenges to mitigation (O’Neill et al. 2017, Bauer et al. 2018).

The EMF-33 study has led to a number of research articles, including an overview of the scenarios and projections (Bauer et al. 2018), and a series of thematic papers on the importance and sensitivity of BECCS in mitigation strategies (Muratori et al. 2020), bioenergy and transport sector decarbonization (LeBlanc et al. 2020), bioenergy trade (Daioglou et al. 2020), as well as a detailed assessment of biomass feedstock supply modeling and implications (Rose et al. 2020; Hanssen et al. 2019). The present paper focuses on technoeconomic assumptions of advanced bioenergy technologies and their effect on the use of bioenergy in climate change mitigation strategies.

The analysis of this paper is based on modeling assumptions and projections of ten of the twelve IAMs participating in the EMF-33 project. To understand model behavior, key bioenergy technology assumptions and model dynamics are collected through a survey and detailed results reporting. The survey gathers technology specification details on capital costs, conversion efficiencies, feedstock costs, operation, and maintenance (O\&M) costs (fixed and variable), CCS capture rates, biomass feedstocks, readiness of CCS technologies, technology lifetimes, the representation of technological change, and emission factors. Bioenergy technoeconomic parameters are then compared with the available literature and expert opinion, 
and the projected bioenergy deployment strategies of the models are linked to methodological choices and assumptions.

For this study, we compare bioenergy technology clusters according to the final energy carrier they produce. These include three different bioliquids (1st generation ethanol, biodiesel, and advanced lignocellulosic based biofuels), electricity, and hydrogen - all with and without CCS. Our comparison presents the cost and efficiency of each technology concerning the primary product as enumerated above. This ignores potential joint products of multioutput conversion technologies like combined heat and power.

The technology specification data and the biomass feedstock prices of each model are used to compute the levelized cost of energy (LCOE) for each bioenergy technology (according to the method detailed in Online Resource 1). While IAMs may not make investment decisions based on LCOE, this indicator is useful as a comparison metric for exploring the economics and competitiveness, and variation in model assumptions and their resulting bioenergy deployments. We then investigate deployment patterns of alternative secondary energy technologies (including bioenergy, renewables, and fossil counterparts) and how they relate to model assumptions. For readability, we focus on global average results, noting that models exhibit significant regional variation in biomass feedstock costs but little regional variation in bioenergy techno-economic parameters (see Online Resource 2, Fig. S1). All regional technoeconomic parameters and results presented in this paper are available online (Supplementary_Data.xlsx).

\section{Bioenergy technology representation}

Most models include technologies for producing hydrogen, liquid fuels, and electricity from biomass (Table 1). However, the production of heat and gaseous fuels tends to not be represented (recognizing that gasification of biomass feedstocks is embedded in other technologies, e.g., biomass-fed IGCC). The conversion technologies utilize broad groups of biomass feedstocks - lignocellulosic crops, food crops, managed forest, miscanthus, and residues (incl. agricultural, forestry, municipal solid waste). This approach ignores potential differences between feedstocks within a group in technology processes, costs, efficiencies, learning, and readiness. All models have some form of advanced biofuel technology based on a lignocellulosic feedstock - crops, residues, or biomass from managed forests. Modeling of biomass feedstock logistics tends to be simple, with cost and/or emission factors for transport (including interregional trade), fertilizer use (usually accounted in the land-use sector), and nonrenewable energy use in the production of biofuels included in most models. While not specifically modeled, feedstock costs may include details such as feedstock seasonality, drying, and storage. Concerning bioenergy with $\mathrm{CO}_{2}$ capture and geologic storage (BECCS) technologies, all models include bioelectricity generation with CCS, while BECCS in hydrogen and liquid fuels is represented in only a subset of the models. This is despite the fact that carbon capture and storage is, in principle, simpler in hydrogen and liquid biofuel production since $\mathrm{CO}_{2}$ is separated as part of the gasification process (Larson et al. 2012). All models assume the availability of BECCS from 2030 onwards, with some models assuming BECCS available as early as 2021. The assumed possibility of significant deployment of BECCS within the next 10 years may be questionable as currently there are only a few pilot projects. Furthermore, there are biophysical, social, and economic obstacles towards faster development and adoption of this technology (Creutzig et al. 2015; Smith et al. 2016). 


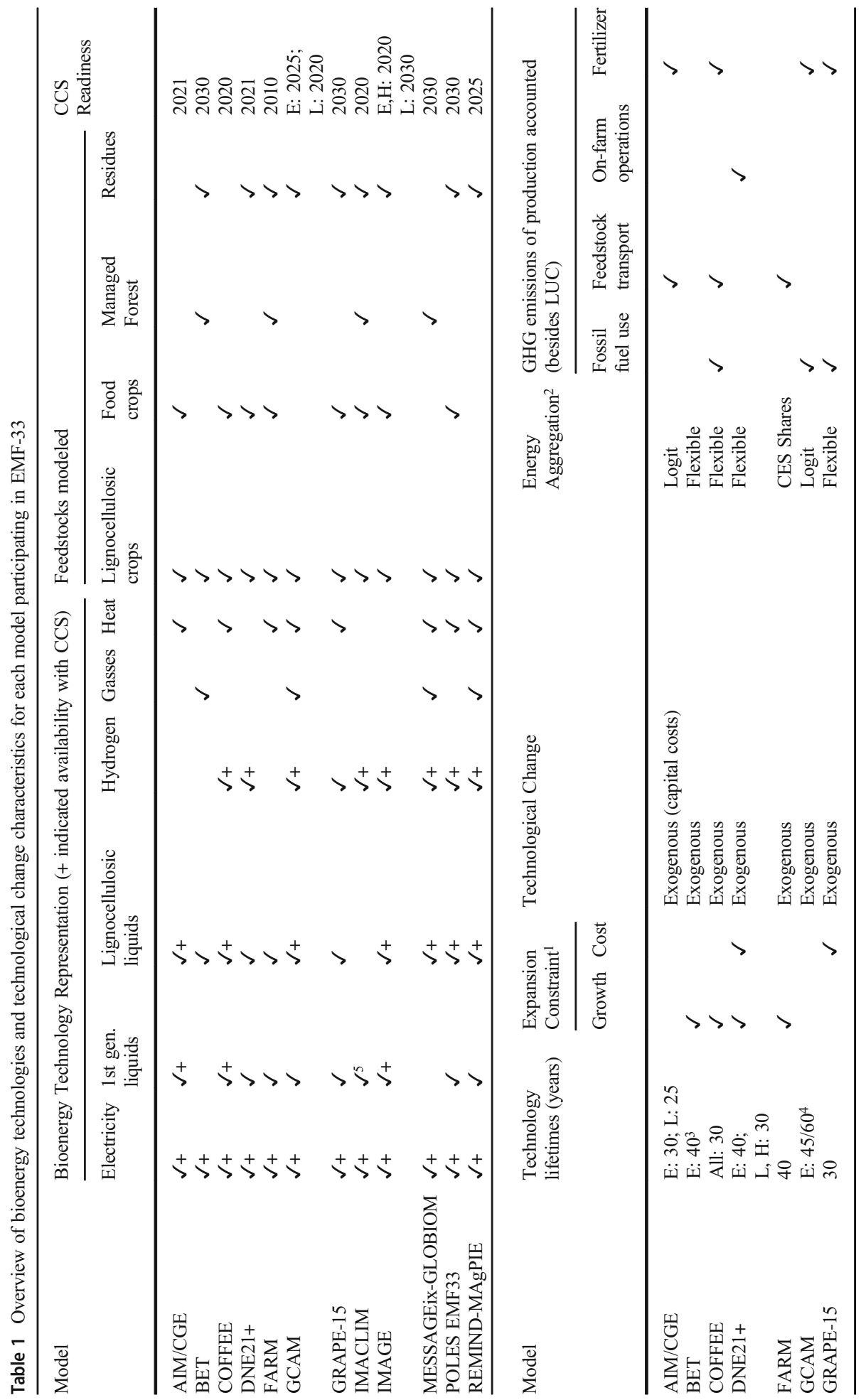




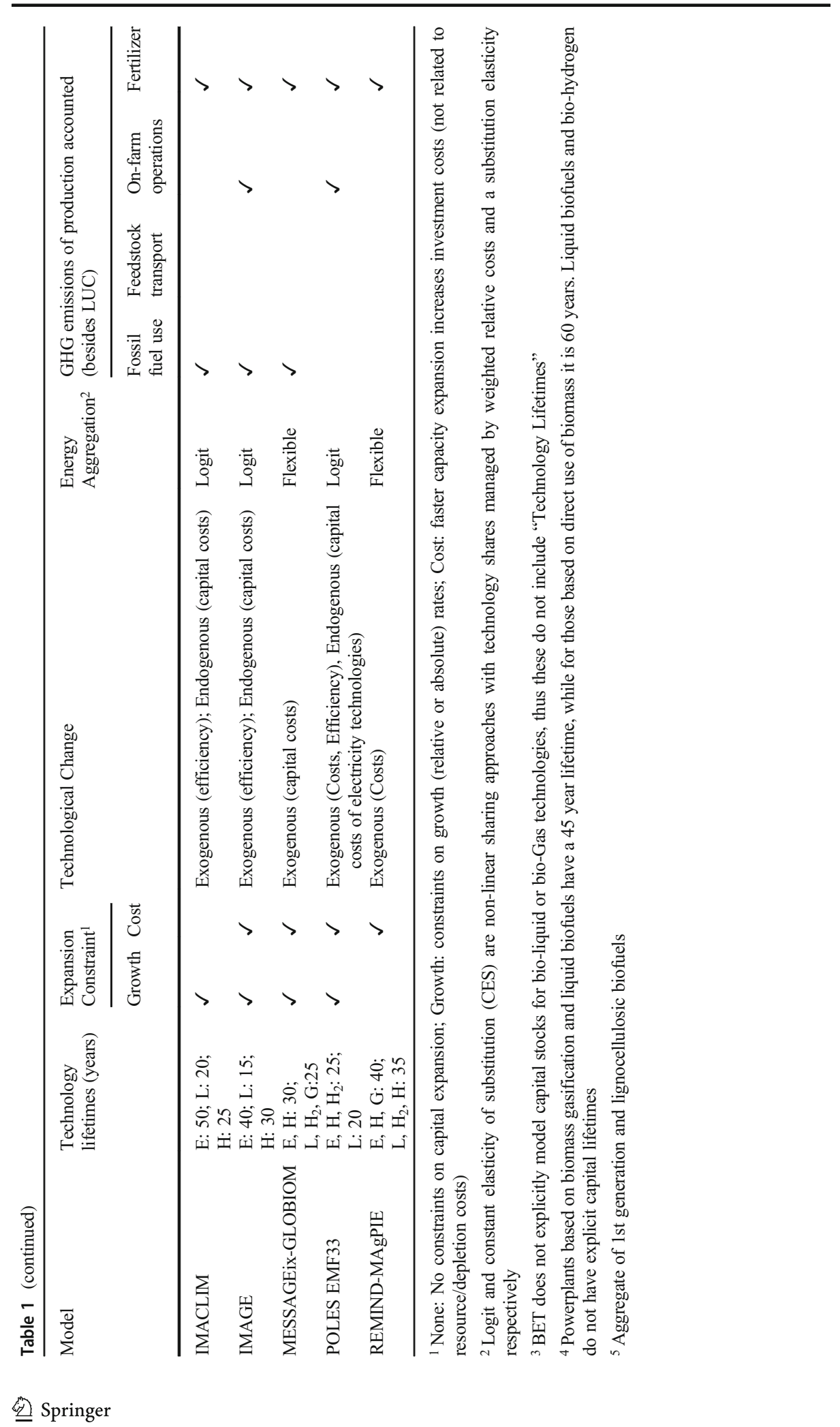


All models include certain assumptions on the dynamics of technoeconomic performance. Most models have exogenous assumptions concerning the improvement of conversion efficiencies and capital costs over time. Alternatively, some models (IMACLIM, IMAGE, and POLES) include endogenous investment cost reductions based on learning-by-doing that are persistent once they are realized. There are, also, differences concerning how models deal with the adoption and ramp-up of new technologies that impose temporary limits on expansion. The flexibility of models to swap between technologies and fuels can be categorized into two broad types: (i) nonlinear sharing with different fuels competing with each other for a market share based on changes in relative prices; and, (ii) flexible models that shift to the cheapest cost alternative. Once marginal technology choices have been made, models also typically have constraints on capacity ramp-up in order to avoid sudden and abrupt changes in technological mixes. Most models tend to limit growth based on a maximum growth rate (BET, DNE21+, FARM, IMACLIM, IMAGE, POLES). The MESSAGEix-GLOBIOM and REMINDMAgPIE models constrain growth rates by applying a penalty on technology costs depending on the growth in capacity additions. For CCS technologies, some models include increasing costs based on depletion of geologic storage resources (DNE21+, GRAPE-15, IMAGE, POLES).

\section{Results}

In the subsections that follow, we assess the techno-economic data and the model representations with respect to deployment patterns. First, we explore the technoeconomic parameterization of bioenergy technologies across models, comparing the assumptions and their projected development to literature and expert opinion. We then use these parameters together with model-specific projections for feedstock costs, carbon price, and emission factors, to calculate LCOEs across technologies and models. Finally, the calculated LCOEs are contrasted to bioenergy deployment levels, and we discuss the bioenergy strategies adopted and their relationship to each model's technology specification.

\subsection{Assessing bioenergy cost parameters}

Figure 2 shows capital costs and conversion efficiency assumptions for bioenergy technologies in 2020. The figure also shows corresponding data from literature reviews - either for existing facilities or from detailed techno-economic analyses (Gerssen-Gondelach et al. 2014; Muratori et al. 2017; Klein et al. 2011; NREL 2015; Larson et al. 2012).

Across models, we observe wide ranges of capital costs for biofuel and bioelectricity technologies. The ranges are for the most part in agreement with the literature, which also exhibits wide ranges. In the literature, the ranges represent, among other things, variation in the size of conversion facilities (i.e., larger scale facilities have lower costs) and the primary feedstocks used. IAMs typically represent technology being scale-free, implicitly assuming a certain size during parameterization, which implies that economies-of-scales are not exploited (see Klein et al. 2011). Model assumptions for the conversion efficiency of 1 st generation ethanol tend to be similar across models, and in agreement with literature. For bioelectricity, advanced biofuels, and biodiesel, while both literature values and model parameters display wide ranges for both capital costs and conversion efficiencies, model assumptions tend to be slightly more optimistic (thus implicitly assuming large scale conversion facilities) but are not 

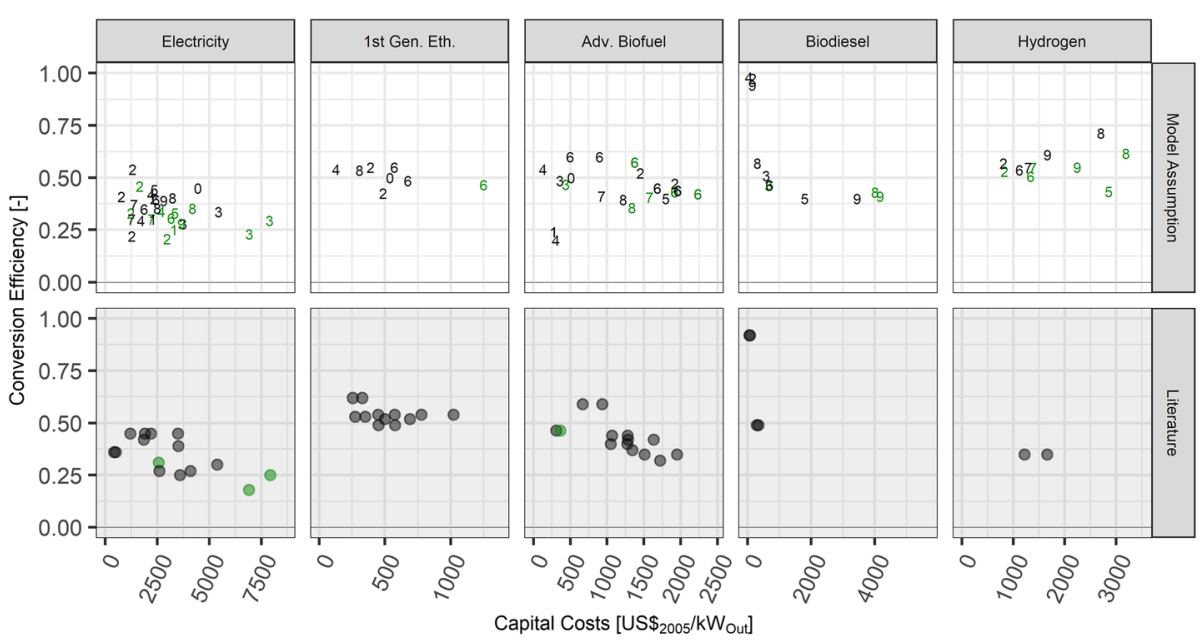

Capital Costs $\left[\mathrm{US} \$ 2005 / \mathrm{kW}_{\text {Out }}\right.$

$\begin{array}{llllllllllll}0 & \text { AIM/CGE } & 2 & \text { DNE21+ } & 4 & \text { GRAPE-15 } & 6 & \text { IMAGE } & 8 & \text { POLES } & \bullet & \text { No CCS } \\ 1 & \text { BET } & 3 & \text { GCAM } & 5 & \text { IMACLIM } & 7 & \text { MESSAGEix-GLOBIOM } & 9 & \text { REMIND-MAgPIE } & \bullet & \text { With CCS }\end{array}$

Fig. 2 Capital costs and conversion efficiencies of bioenergy technologies in 2020 across different IAMs and post-2010 literature. Note, models may have more than one instance of a given technology. Figure shows global mean for each model, regional parameters shown in Online Resource 2

systematically more optimistic than results reported in bottom-up technoeconomic studies. For biohydrogen, the models tend to be quite optimistic concerning conversion efficiency.

Across models, the capital costs of CCS technologies compared to the base costs (i.e., the technology without CCS) increase by $2-242 \%, 10-315 \%$, and $3-35 \%$ for electricity, liquids, and hydrogen, respectively. The penalty on conversion efficiencies (percentage points) due to the integration of CCS is $0-15 \%, 0-10 \%$, and $0-12 \%$ respectively. Note that the full ranges presented here are heavily skewed; refer to Online Resource 2 for histograms of these penalties. Literature data for CCS technologies are limited to results from process modeling studies. These suggest that models are generally optimistic (especially for bioelectricity) about the additional capital cost and efficiency loss when a technology is equipped with CCS.

To assess projected costs and efficiencies, we compare the ranges of model results (full ranges shown, see Online Resource 2 for histograms of ranges) with an expert elicitation (Baker et al. 2015). Baker et al. (2015) gathered expert opinion on the expected future (2030) cost and efficiency of, among other things, advanced bioenergy technologies for different levels of R\&D investments. For bioelectricity without CCS, the model range in 2030 for efficiency is $24-56 \%$. According to Baker et al.'s expert elicitation, the expected efficiencies in 2030 for this technology are approximately $20-30 \%, 25-35 \%$, and 30-50\% for "low", "medium", and "high" levels of research and development respectively. Concerning nonenergy costs of bioelectricity, the expert elicitation returned ranges of 30-90, 20-70, and 20-45 $\$ 2005$ /MWh for "low", "medium", and "high" R\&D levels, respectively. This compares with the model range for nonenergy costs of 11-109 $\$ 2005 / \mathrm{MWh}$ (with most values below $50 \$_{2005} /$ MWh, see Online Resource 2). ${ }^{1}$ For bioliquids efficiency in 2030, expert elicitation ranges are $35-45 \%, 40-80 \%$, and $45-75 \%$ respectively, while the model range for the equivalent

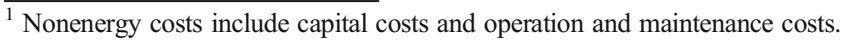


technologies is $20-60 \%$. Nonenergy costs for bioliquids in 2030 from the expert elicitation are $20-70,15-60$, and 15-55 \$/2005 MWh respectively, and for the models $0.2-53 \$ 2005 / \mathrm{MWh}$.

The cost and efficiency penalties of equipping bioenergy technologies with CCS are projected to decrease over time across all models. The expert elicitation in Baker et al. (2015) highlighted CCS costs of 410-1235, 80-905, and 40-905 $\$ 2005 / \mathrm{kW}$ for "low", "medium", and "high" R\&D levels respectively. The IAMs investigated here show ranges of 58$2854 \$_{2005} / \mathrm{kW}$ (liquids) and 87-2748 $\$ 2005 / \mathrm{kW}$ (electricity).

Overall, the above comparisons indicate that while IAM projections of the costs and efficiencies of bioenergy technologies are somewhat optimistic, they are generally in line with the expectations of experts. However, experts expect that realizing these technological improvements requires $R \& D$ expenditures two to ten times greater than current $R \& D$ levels of OECD countries - approximately $360 \mathrm{M} \$_{2005} /$ year (OECD 2018; Baker et al. 2015). For further details on the modeled ranges of different cost components and how they relate to the expert elicitation, see Online Resource 2.

\subsection{Assessing bioenergy deployment costs}

Using the gathered technoeconomic data we calculate the levelized cost of different energy carriers in order to better understand differences in projected bioenergy deployment between models. As shown in the Online Resource 1, the LCOE includes model specific capital, O\&M, feedstock, and emission costs, including payments for carbon dioxide removal (CDR) in the case of BECCS technologies. In the calculation of the LCOEs, all parameters are based on model and scenario specific assumptions/projections except for discount rates and capacity factors for renewables. The calculation of each cost component follows the IPCC methodology in Krey et al. (2014) with two exceptions, ${ }^{2}$ and our LCOE calculations are based on the EMF33 policy scenario with a cumulative energy and industry $\mathrm{CO}_{2}$ emissions budget of 1000 billion metric tons of $\mathrm{CO}_{2}\left(\mathrm{GtCO}_{2}\right)$ over the 2011-2100 period with each models' default technologies available.

Figure 3 presents 2030, 2050, and 2100 levelized costs for each model for bioelectricity, advanced biofuels, biodiesel, and biohydrogen, with and without CCS. A progression of LCOEs for bioenergy are calculated for technologies, starting with capital and O\&M costs alone (top row), adding in biomass feedstock costs (middle row), and finally adding in CDR payments (bottom row). For additional details regarding capital and O\&M cost assumptions and levelized costs, see Online Resources 2 and 3. Note that some models have multiple instances of a given technology, all of which are displayed. Most models show a modest reduction in capital and O\&M costs over time, driven by learning, which may be endogenous (IMAGE and IMACLIM), exogenous (BET, DNE21, GCAM, GRAPE, MESSAGEixGLOBIOM, and REMIND-MAgPIE), or a combination of both (POLES). Models with endogenous learning display positive feedback loops for specific technologies, where increased adoption leads to further cost reductions, making it even more competitive. On the other hand, if a technology is not adopted in these models, we observe little or no improvement in capital costs. For instance, in the IMAGE results, only one lignocellulosic biofuel technology exhibits significant cost reductions because it is being deployed (see Online Resource 3).

\footnotetext{
${ }^{2}$ The calculation here differs from the IPCC methodology in that we include payments for CDR, and do not include decommissioning costs as these costs are not included in IAMs. Decommissioning costs, however, may be substantial, especially for nuclear power.
} 
In all models, increased use of bioenergy is driving up feedstock prices throughout the projection period, with feedstock costs eventually dwarfing other cost components, especially after 2050. Feedstock costs are projected to represent 12-99\% of the LCOE by 2030, see (Online Resource 2). ${ }^{3}$ By the end of the century, there are substantial increases in the LCOEs for all models, but particularly for BET, DNE21+, and IMACLIM, all of which see midcentury LCOEs (excluding CDR) in excess of $500 \$ 2005 / \mathrm{MWh}$. Note that biomass cost-supply curves are model specific, and, for some models, biomass feedstock costs are also a function of land GHG mitigation incentives (e.g., land carbon and $\mathrm{N}_{2} \mathrm{O}$ ), see Rose et al. (2020). For DNE21+, GRAPE, IMACLIM, IMAGE, MESSAGEix-GLOBIOM, and REMIND-MAgPIE, feedstock costs increase with demand, as well as increasing prices for land-related GHG emissions that, among other things, value direct and indirect emissions from biomass feedstock production. Additionally, besides biomass feedstock costs rising with carbon prices, previous IAM studies have shown that feedstock costs also reflect rising prices for food products (Muratori et al. 2016; Klein et al. 2014). Overall, feedstock costs are also the cost component with the greatest regional variations and uncertainty across models (see Supplementary Data and Online Resource 2 for details).

The LCOEs with CDR payments illustrate the potential for significant CDR revenues for BECCS technologies if the carbon removals are remunerated, with revenues increasing over time as the cumulative carbon constraint increasingly binds. The revenues result in partial to more than complete compensation for rising feedstock costs, with negative overall costs possible after midcentury. As shown in Online Resource 4, LCOEs of BECCS technologies become negative at carbon prices greater than $\approx 250 \$_{2005} / \mathrm{tCO}_{2}$ for most models. Also, it is worth noting that the models/technologies with the lowest overall LCOE tend to be those which have the highest capture rates. Interestingly, while the DNE21+ and GCAM models project the highest carbon price, these models do not display negative BECCS LCOEs, largely due to their very high feedstock costs.

\subsection{Assessing bioenergy technology deployment}

As shown in Fig. 1 and Bauer et al. (2018), the EMF-33 models adopt vastly different bioenergy technology deployment strategies in meeting a particular climate objective. A number of factors help explain the deployment differences. In this section, we explore the relationship between bioenergy deployment and relative technology costs - contrasting biomass, renewables and fossil technologies - and integration constraints in biomass allocation across end-uses.

In a framework based solely on static costs, the technology with the lowest cost would supply the overall market, which implies dramatic shifts between technology investments (also known as "penny-switching" and "bang-bang behavior"). However, in IAMs, investment decisions are not based only and simply on costs, like the LCOE estimates in section 4.2. Instead, IAMs also consider transitional and system integration factors, as well as market dynamics, that are relevant for technology deployment and overall energy system pathways. These include constraints on capacity expansion of innovative technologies, capital turnover of incumbent technologies, market share constraints for individual technologies, and in the case of CCS technologies, limitations on geological injection of $\mathrm{CO}_{2}$ (Muratori et al. this issue). Therefore, while cost is an important indicator for technology deployment at the individual plant level, system integration factors are crucial in determining overall deployment and energy system transformation.

\footnotetext{
${ }^{3}$ Range based on technologies without CCS. Inclusion of CCS can lead to negative LCOEs.
} 
Transitional and system integration factors can trigger early investments to overcome barriers for innovative technologies or they can constrain expansion when limits are reached. Barriers considered in IAMs are high start-up and investment costs that are decreased by technological learning (endogenous or exogenous) or limitations on capacity expansion. Intertemporal optimization models (BET, DNE21, GRAPE, MESSAGEix, REMINDMAgPIE) anticipate such barriers, triggering early investments to overcome them. In this case, technology ramp-up would start although costs exceed the market price. Conversely, if the barriers are not anticipated, as is the case in models that solve for recursive dynamic pathways (AIM/CGE, GCAM, IMACLIM, IMAGE, POLES), the barriers act as hard constraints on technology ramp-up. Unless the cost falls below the market price, the ramp-up cannot be accelerated. Moreover, during a transition phase, the costs of incumbent technologies that phase out of the system are higher than the cost of the innovative technology that is in a growth phase. The large capacity stock of the incumbent technology, if not decommissioned either through early retirement or by reaching its technical lifetime, can act as a growth limitation for the innovative technology. These barriers are relevant at early stages of the innovation cycle and are mostly technology specific.

As technologies are scaled-up, gaining larger shares in the energy mix, system-wide constraints can limit expansion. For example, the economic and physical limitations of biomass feedstock availability are highly relevant, especially for the second half of the century. These limitations are reflected in higher feedstock market prices and their influence on the LCOE (Fig. 3). Additionally, increases in the share of bioenergy in various market segments may lead to integration challenges, and thus differences in the LCOE of technologies that simultaneously penetrate the market. As described in section 3, integration challenges are modeled by nonlinear sharing approaches or limitations on market share, which can be hard bounds or cost mark-ups that increase with market share (Table 1). For BECCS technologies, geological storage space and limitations on the rate of CDR can constrain expansion and result in market prices higher than the calculated LCOE for BECCS technologies.

Figure 4 shows, for each model, the 2050 deployment of bioenergy, and competing technologies, relative to their total levelized cost (capital, O\&M, feedstock and CDR costs). The arrows show the direction in which the technologies move in the two-dimensional LCOE-deployment space through to 2100 (full 2050-2100 trajectory of each technology are available in Online Resource 5). Panel A presents the relative deployments and costs for bioliquids and fossil-based liquids, while panel B presents deployments and costs for electricity production for bioenergy, renewables, nuclear, and fossil-based technologies. The deployment and market share of each technology depends on the model flexibility for substituting between energy conversion technologies. Table 1 mentioned that some models allow for nonlinear sharing of different technologies (AIM/CGE, GCAM, IMACLIM, IMAGE, POLES), and others allow full-flexibility where fuel mixes shift towards the cheapest option, subject to constraints (BET, DNE21+, GRAPE, MESSAGEix-GLOBIOM, REMINDMAgPIE). Models with nonlinear sharing formulations project investments in and operation of technologies other than the cheapest, with market shares usually based on relative costs.

While model flexibility drives the long-term substitution between conversion technologies, it does not explain the persistent use of more expensive technologies in the near-term, particularly for liquids. This result is due, in part, to energy system inertia modeled via constraints in technological change and substitution. This helps explain the relatively high deployment of fossil fuels in 2050 despite their high costs due to the carbon price. Constraints in capacity ramp-up and decommissioning of existing capital (see Table 1) lead to lower deployment of bioenergy (and other low-carbon options) in the first half of the twenty-first 

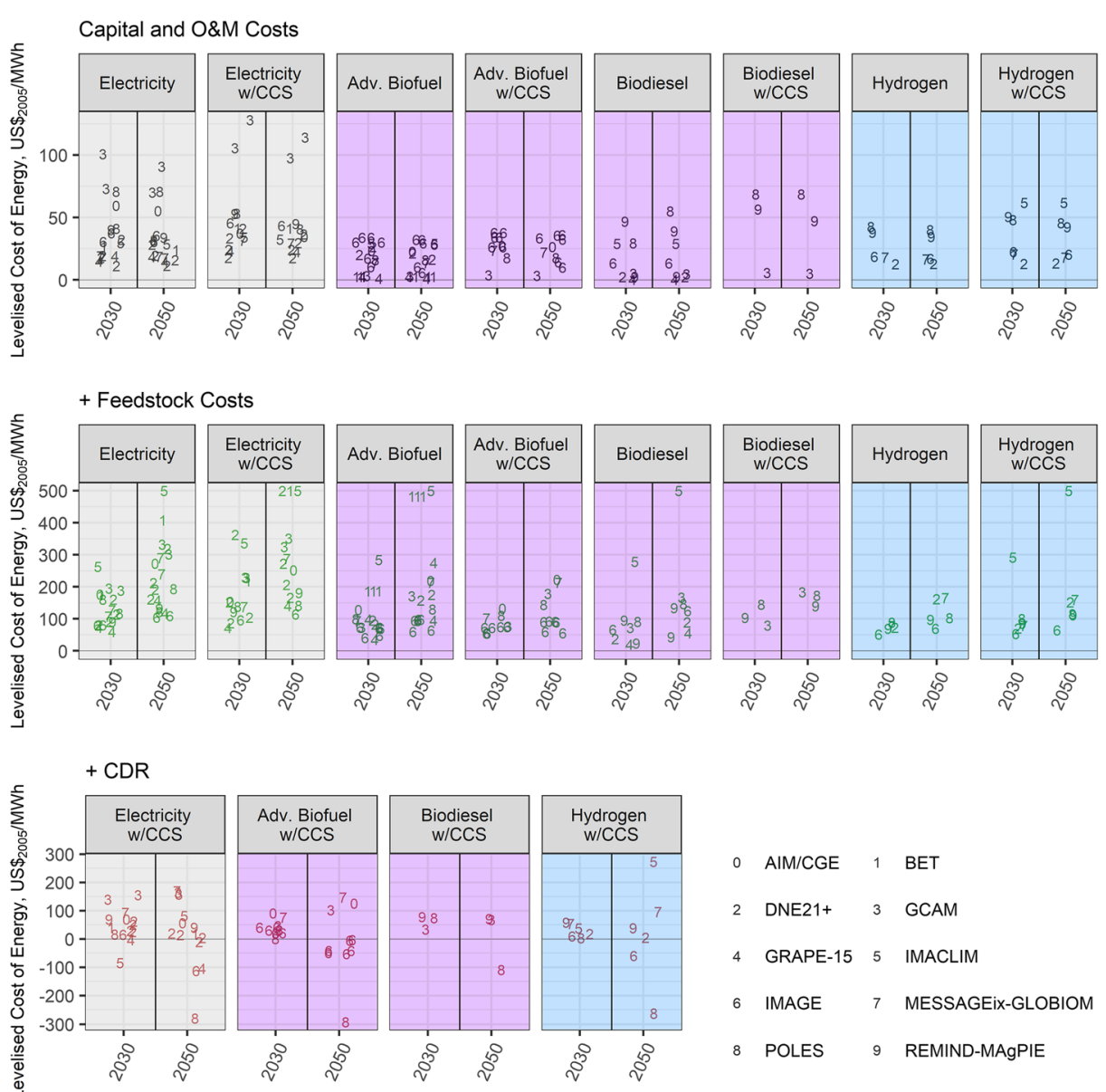

Fig. 3 Bioenergy LCOEs inclusive of different costs components: capital + O\&M costs (top), with feedstock costs (middle), and with CDR costs (bottom). Results shown for 2030 and 2050. $Y$-axis' scales vary and are limited to $\pm 500 \mathrm{US}_{2005} / \mathrm{MWh}$. Note: These LCOEs are estimated based on the technoeconomic parameters of the models. The models themselves may not base their projections on LCOEs

century. In most models, the inertia in technological change has been largely overcome by 2100 , resulting in more prominent use of low LCOE options, and bioenergy in particular.

How biomass is cost-effectively allocated across bioenergy uses also depends on the broader energy sector context in which they are used. GCAM, MESSAGEix-GLOBIOM, and REMINDMAgPIE show a rapid post-2050 phase out of fossil-based liquids, highlighting that biobased liquids are the preferred bioenergy technology. However, this is not the case for most models despite the heavy penalties on fossil-based liquids imposed by the carbon price. This raises further questions about how models allocate biomass between liquid or electricity conversion processes. BET and DNE21+ focus their biomass conversion on electricity (while also deploying significant levels of other renewables). These models, however, do not include a liquids BECCS option and also project some of the lowest levels of energy demand by simulating demand side mitigation measures such as efficiency improvements. For instance, they project low energy demand for transport, easing the pressure for decarbonizing the sector through the production of low-carbon 
liquid fuels. In contrast, GCAM, MESSAGEix-GLOBIOM, and REMIND-MAgPIE prefer to convert biomass to liquid fuels. Each of these models features high levels of nonbioenergy renewable electricity production and the possibility of bioliquids with BECCS. As shown in Bauer et al. (2018), these models apply either optimistic assumptions for the availability of nonbiomass renewables, or nonbinding constraints on capacity ramp-up. This leads to a mitigation strategy where electricity is decarbonized through the rapid and large-scale deployment of nonbiomass renewables, and conversion of biomass to liquids together with CCS. IMACLIM also projects the production of liquid fuels, but for different reasons as it lacks the liquids BECCS option. IMACLIM projects the lowest overall energy demand across all models, and its electricity sector is decarbonized relatively easily by renewables, with biomass decarbonizing the transport sector through conversion to liquids even though CCS cannot be added to the conversion process. Due to its overall low energy demand, IMACLIM depends on BECCS the least of all models, with BECCS accounting for $1.5 \mathrm{GtCO}_{2}$-eq/year in 2100, compared with 8-25GtCO2-eq/year from the other models. POLES, IMAGE, AIM/CGE, and GRAPE allocate biomass to liquids and electricity more equally than the other models. This is because these models face stricter constraints on the deployment of other renewable electricity options, resulting in decarbonization of the electric sector using multiple options (including BECCS and other renewable options), and conversion of biomass to liquid fuels to aid decarbonization of the transport sector.

\section{Conclusions}

This study has elucidated the characterizations of bioenergy technologies in IAMs and how they relate to technology deployment in scenarios likely to limit global average temperature to below $2{ }^{\circ} \mathrm{C}$. The results highlight differences in the representation of bioenergy technologies, and the drivers and constraints of large scale adoption. Crucially, the results show that projected bioenergy deployment is only partially dependent on technoeconomic parameterization, with biomass feedstock availability and $\mathrm{CO}_{2}$ cost being crucial factors. This finding is in agreement with previous studies which investigated the projections of different models under harmonized technoeconomic assumptions (Bosetti et al. 2015; Krey et al. 2019).

A number of general conclusions can be drawn from this analysis:

Bioenergy technology coverage and characterizations vary substantially While most models include biobased electricity and liquid biofuels, their coverage of other technology pathways (hydrogen, gasses) is limited. This is particularly important concerning biogases since all the models that include this technology (BET, MESSAGEix-GLOBIOM, and REMIND-MAgPIE) tend to adopt it to some extent. Furthermore, while all models include a CCS option for bioelectricity, this is not the case for liquids and hydrogen. Concerning the scaling-up of advanced bioenergy technologies, besides competition with other energy options (fossil, renewable, nuclear), IAMs have limits on the annual growth of given technologies. These differ across models and are based either on limits on allowed growth rates, adjusted costs depending on desired growth, or in the case of CCS technologies, depletion of geologic storage. Logistical issues which may hamper the large-scale utilization of bioenergy such as seasonality and pre-processing of feedstocks are not explicitly dealt with in any of the models. 
a DEPLOYMENT OF LIQUID TECHNOLOGIES
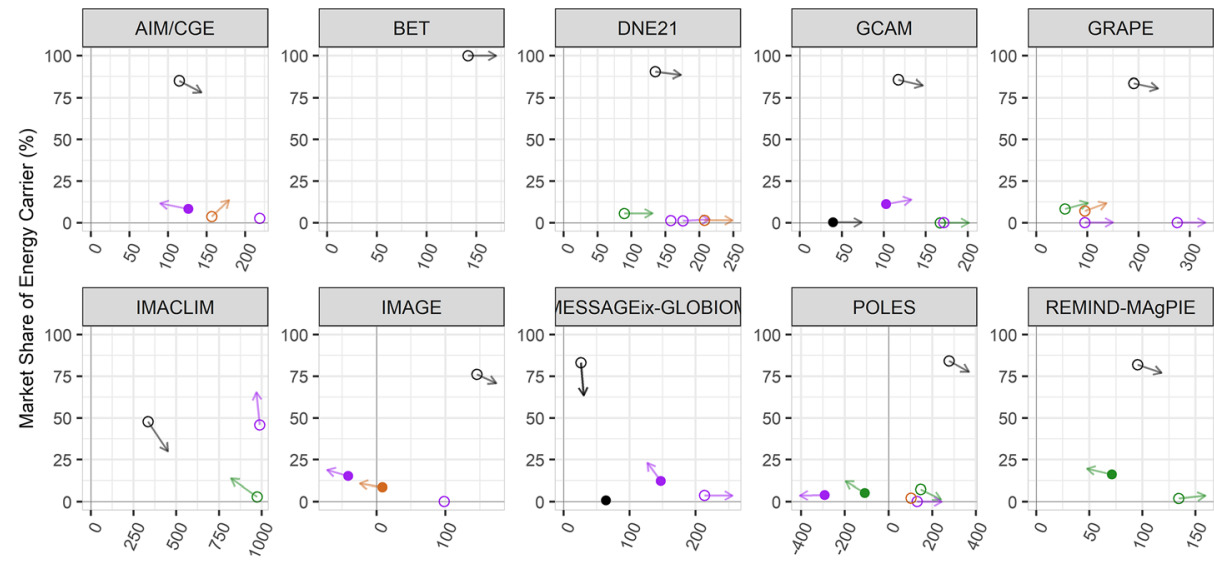

Levelised Cost of Energy, US $\$_{2005} / \mathrm{MWh}$

CONVERSION TECHNOLOGY: $\bullet$ 1st Gen. Eth. $\rightarrow$ Biodiesel $\rightarrow$ Adv. Biofuel $\bullet$ Fossil

ccs: o No css

With CCS

\section{b DEPLOYMENT OF ELECTRICITY TECHNOLOGIES}
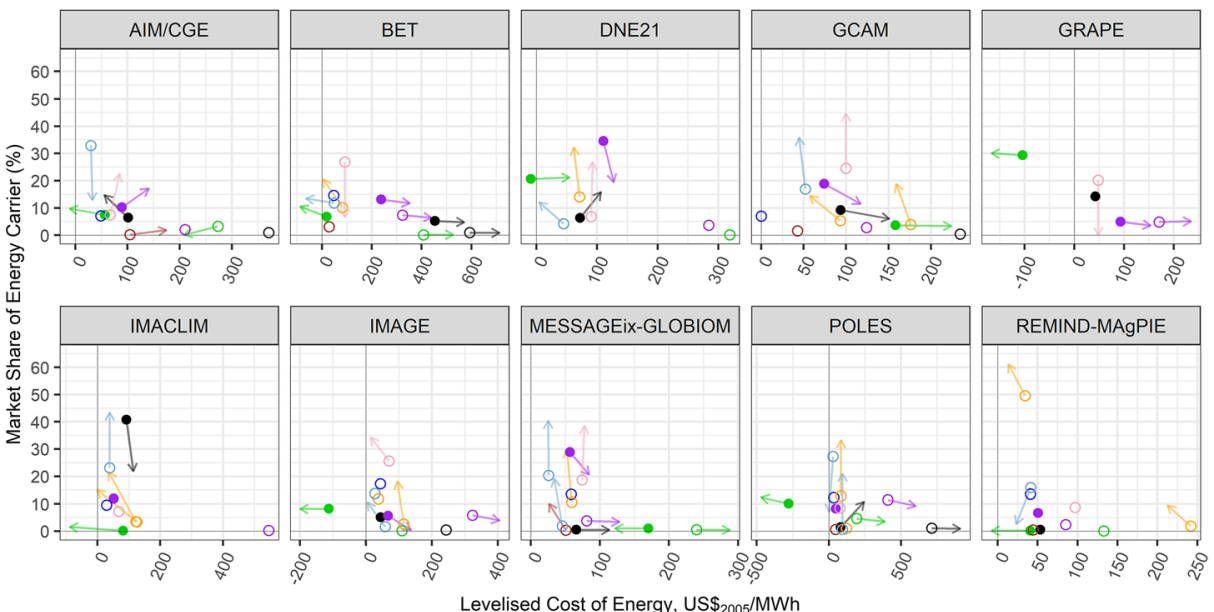

Levelised Cost of Energy, US $\$ 2005 / \mathrm{MWh}$

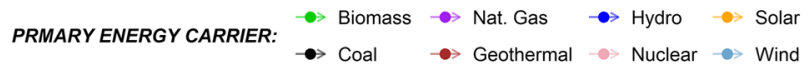

ccs: $\circ$ No CSS - With CCS

Fig. 4 Deployment of different a liquids and $\mathbf{b}$ electricity energy carriers relative to levelized costs for 2050 and their post-2050 trajectory direction. $X$-axis' scales vary by model. LCOEs include capital, O\&M, feedstock and CDR costs. Line lengths do not show magnitude of change, only direction. For projected post-2050 changes see online supplementary data and Online Resource 5. Only technologies with a nonnegligible deployment shown and technologies without arrows cease to be deployed in the 2nd half of the twenty-first century 
The technoeconomic assumptions of IAM models are largely in line with bottom-up estimates. However, both model assumptions and bottom-up estimates vary widely Bioenergy technology capital costs and efficiencies are in line with the literature and expectations of experts assuming annual R\&D expenditures more than double over the next few years. These expenditures would have to focus on the development of advanced technologies such as lignocellulosic biofuels and BECCS. If these improvements do not take place, mitigation costs and the model infeasibility of scenarios could increase substantially as shown in Bauer et al. (2018). Though there is limited data on the additional costs of CCS, models appear somewhat optimistic about both the added costs and the efficiency penalty this technology may have.

\section{Bioenergy conversion costs are primarily driven by biomass feedstock costs and CDR} payments In high bioenergy demand projections, most models show a modest reduction in capital and O\&M costs over time, with little variation across models. Feedstock costs are the main (and most uncertain) cost component of bioenergy for technologies without CCS. For bioenergy with CCS, payments from $\mathrm{CO}_{2}$ removal could be substantial and more than offset feedstock and other costs.

\section{Variation in bioenergy deployment across models cannot be understood from technol-} ogy costs alone While costs may be important for selecting specific facilities, the use of bioenergy in mitigation strategies is driven by a combination of factors. Important determinants include feedstock costs, the availability and costs of alternative mitigation options for different end-uses, the availability of CDR and potential payments, the speed with which large scale changes in the makeup of energy conversion facilities and integration can take place, and the relative demand for different energy services.

Acknowledgements The views and opinions expressed in this paper are those of the authors alone and do not reflect the positions of their institutions or governments. S. Fujimori was supported by the Environment Research and Technology Development Fund (JPMEERF20202002) of the Environmental Restoration and Conservation Agency of Japan and the Sumitomo Foundation.

Open Access This article is licensed under a Creative Commons Attribution 4.0 International License, which permits use, sharing, adaptation, distribution and reproduction in any medium or format, as long as you give appropriate credit to the original author(s) and the source, provide a link to the Creative Commons licence, and indicate if changes were made. The images or other third party material in this article are included in the article's Creative Commons licence, unless indicated otherwise in a credit line to the material. If material is not included in the article's Creative Commons licence and your intended use is not permitted by statutory regulation or exceeds the permitted use, you will need to obtain permission directly from the copyright holder. To view a copy of this licence, visit http://creativecommons.org/licenses/by/4.0/.

\section{References}

Anderson K, Peters G (2016) The trouble with negative emissions. Science 354:182-183

Baker E, Bosetti V, Anadon LD, Henrion M, Aleluia Reis, L. (2015) Future costs of key low-carbon energy technologies: harmonization and aggregation of energy technology expert elicitation data. Energy Policy 80 : 219-232

Bauer N, Rose S, Fujimori S, Van Vuuren D, Weyant J, Wise M, Cui Y, Daioglou V, Gidden M, Kato E, Kitous A, Leblanc F, Sands R, Sano F, Strefler J, Tsutsui J, Bibas R, Fricko O, Hasegawa T, Klein D, Kurosawa A, Mima S, Muratori M (2018) Global energy sector emission reductions and bio-energy use: overview of the EMF-33 model comparison. Clim Chang:1-16

Bosetti V, Marangoni G, Borgonovo E, Diaz Anadon L, Barron R, Mcjeon HC, Politis S, Friley P (2015) Sensitivity to energy technology costs: a multi-model comparison analysis. Energy Policy 80:244-263 
Buck HJ (2016) Rapid scale-up of negative emissions technologies: social barriers and social implications. Clim Chang 139:155-167

Bui M, Adjiman CS, Bardow A, Anthony EJ, Boston A, Brown S, Fennell PS, Fuss S, Galindo A, Hackett LA, Hallett JP, Herzog HJ, Jackson G, Kemper J, Krevor S, Maitland GC, Matuszewski M, Metcalfe IS, Petit C, Puxty G, Reimer J, Reiner DM, Rubin ES, Scott SA, Shah N, Smit B, Trusler JPM, Webley P, Wilcox J, Mac Dowell, N. (2018) Carbon capture and storage (Ccs): the way forward. Energy Environ Sci

Clarke L, Jiang K, Akimoto K, Babiker MGB, Fisher-Vanden K, Hourcade JC, Krey V, Kriegler E, Löschel A, McCollum D, Paltsev S, Rose S, Shukla PR, Tavoni M, Van Der Zwaan B \& Van Vuuren DP (2014) Assessing transformation pathways. In: Edenhofer, O., Pichs-Madruga, R., Sokona, Y., Farahani, E., Kadner, S., Seyboth, K., Adler, A., Baum, I., Brunner, S., Eikemeier, P., Kriemann, B., Savolainen, J., Schlömer, S., Von Stechow, C., Zwickel, T. \& Minx, J. C. (eds.) Climate change 2014: Mitigation of Climate Change. Contribution of Working Group III to the Fifth assessment Report of the Intergovernmental Panel on Climate Change. Cambridge, United Kingdom and New York, NY, USA: Cambridge University press

Creutzig F, Ravindranath NH, Berndes G, Bolwig S, Bright R, Cherubini F, Chum H, Corbera E, Delucchi M, Faaij A, Fargione J, Haberl H, Heath G, Lucon O, Plevin R, Popp A, Robledo-Abad C, Rose S, Smith P, Stromman A, Suh S, Masera O (2015) Bioenergy and climate change mitigation: an assessment. GCB Bioenergy 7:916-944

Daioglou V, Muratori M, Lamers P, Fujimori S, Kitous A, Bauer N, Junginger HM, Kato E, Koberle A, Leblanc F, Mima S, Wise M, Van Vuuren D (2020) Implications of climate change mitigation scenarios on international bioenergy trade. Clim Chang (in review)

Field CB, Mach KJ (2017) Rightsizing carbon dioxide removal. Science 356:706-707

Fuss S, Canadell JG, Peters GP, Tavoni M, Andrew RM, Ciais P, Jackson RB, Jones CD, Kraxner F, Nakicenovic N, LE QuérÉ C, Raupach MR, Sharifi A, Smith P, Yamagata Y (2014) Betting on negative emissions. Nat Clim Chang 4:850-853

Gerssen-Gondelach SJ, Saygin D, Wicke B, Patel MK, Faaij APC (2014) Competing uses of biomass: assessment and comparison of the performance of bio-based heat, power, fuels and materials. Renew Sust Energ Rev 40:964-998

Hanssen SV, Daioglou V, Steinmann ZJN, Frank S, Popp A, Brunelle T, Lauri P, Hasegawa T, Huijbregts MAJ, Van Vuuren P (2019) Biomass residues as twnety-first century bioenergy feedstock - a comparison of eight integrated assessment models. Clim Chang 1-18

Klein D, Bauer N, Bodirsky B, Dietrich JP, Popp A (2011) Bio-IGCC with CCS as a long-term mitigation option in a coupled energy-system and land-use model. Energy Procedia 4:2933-2940

Klein D, Luderer G, Kriegler E, Strefler J, Bauer N, Leimbach M, Popp A, Dietrich JP, Humpenöder F, LotzeCampen H, Edenhofer O (2014) The value of bioenergy in low stabilization scenarios: an assessment using REMIND-MAgPIE. Clim Chang 123:705-718

Krey V, Masera O, Blanford GJ, Bruckner T, Cooke R, Fisher-Vanden K, Haberl H, Hertwich E, Kriegler E, Mueller D, Paltsev S, Price L, Schlömer S, Ürge-Vorsatz D, Van Vuuren D \& Zwickel T (2014) Annex II: Metrics \& Methodology. In: Edenhofer, O., Pichs-Madruga, R., Sokona, Y., Farahani, E., Kadner, S., Seyboth, K., Adler, A., Baum, I., Brunner, S., Eickemeier, P., Kriemann, B., Savolainen, J., Schlömer, S., Von Stechow, C., Zwickel, T. \& Minx, J. C. (eds.) Climate Change 2014: Mitigation of Climate Change. Contribution of Working Group III to the Fifth Assessment report of the Intergrovernmental Panel on Climate Change. Cambridge, United Kingdom and New York, NY, USA: Cambridge University press

Krey V, Guo F, Kolp P, Zhou W, Schaeffer R, Awasthy A, Bertram C, DE Boer HS, Fragkos P, Fujimori S, He C, Iyer G, Keramidas K, Koberle A, Oshiro K, Reis LA, Shoai-Tehrani B, Vishwanathan S, Capros P, Drouet L, Edmonds JE, Garg A, Gernaat D, Jiang K, Kannavou M, Kitous A, Kriegler E, Luderer G, Mathur R, Muratori M, Sano F, Van Vuuren D (2019) Looking under the hood: A comparison of techno-economic assumptions across national and global integrated assessment models. Energy 172:1254-1267. https://doi.org/10.1016/j.energy.2018.12.131

Kriegler E, Weyant JP, Blanford GJ, Krey V, Clarke L, Edmonds J, Fawcett A, Luderer G, Riahi K, Richels R, Rose S, Tavoni M, Van Vuuren DP (2014) The role of technology for achieving climate policy objectives: overview of the EMF27 study on global technology and climate policy strategies. Clim Chang 123:353-367

Larson ED, Li Z, \& Williams RH (2012) Chapter 12-fossil energy. In Global Energy Assessment-Toward a Sustainable Future. Cambridge University press, Cambridge, UK and New York, NY, USA and the International Institute for Applied Systems Analysis, Laxenburg, Austria, pp. 901-992

Leblanc F, Bibas R, Mima, S, Muratori M, Sakamoto S, Sano F, Bauer N, Daioglou V, Fujimori S, Gidden MJ, Kato E, Tsutsui J, Wise M (2020) The contribution of bioenergy to the decarbonization of transport: a multimodel assessment. Clim Chang (in review)

Lomax G, Lenton TM, Adeosun A, Workman M (2015) Investing in negative emissions. Nat Clim Chang 5:498

Luckow P, Wise MA, Dooley JJ, Kim SH (2010) Large-scale utilization of biomass energy and carbon dioxide capture and storage in the transport and electricity sectors under stringent $\mathrm{CO} 2$ concentration limit scenarios. Int J Greenh Gas Con 4:865-877 
Muratori M, Calvin K, Wise M, Kyle P, Edmonds J (2016) Global economic consequences of deploying bioenergy with carbon capture and storage. Environ Res Lett 11:9

Muratori M, Kheshgi H, Mignone B, Clarke L, Mcjeon H, Edmonds J (2017) Carbon capture and storage across fuels and sectors in energy system transformation pathways. Int J Greenh Gas Con 57:34 41

Muratori M, Bauer B, Rose SK, Wise M, Daioglou V, Cui Y, Kato E, Gidden MJ, Strefler J, Fujimori S, Sands RD, van Vuuren DP, Weyant J (2020) EMF-33 Insights on Bioenergy with Carbon Capture and Storage (BECCS). Clim Chang (accepted)

NREL (2015) 2015 standard scenarios annual report: U.S. electric sector scenario exploration. In: Sullivan P, Cole W, Blair N, Lantz E, Krishan V, Mai T, Mulchay D, Porro G (eds) National Renewable Energy Laboratory (NRELL), Golden

OECD (2018) Energy Technology RD\&D (2017 edition). Paris, France: International Energy Agency

O'neill BC, Kriegler E, Edi KL, Kemp-Benedict E, Riahi K, Rothman DS, Van Ruijven BJ, Van Vuuren DP, Birkmann J, Kok K, Levy M, Solecki W (2017) The roads ahead: narratives for shared socioeconomic pathways describing world futures in the $21^{\text {st }}$ century. Glob Environ Chang 42:169-180

Rose S, Kriegler E, Bibas R, Calvin K, Popp A, Van Vuuren DP, Weyant JP (2014) Bioenergy in energy transformation and climate management. Clim Chang 123:477-493

Rose S, Popp A, Fujimori S, Havlik P, Van Vuuren D, Weyant J, Wise M (2020) Global biomass supply modeling for long-run management of the climate system. Clim Chang (in review)

Smith P, Davis S, Creutzig F, Fuss S, Minx JC, Gabrielle B, Kato E, Jackson RB, Cowie A, Kriegler E, Van Vuuren D, Rogelj J, Ciais P, Milne J, Canadell JG, McCollum D, Peters GP, Andrew RM, Krey V, Shrestha G, Friedlingstein P, Gasser T, Grübler A, Heidug W, Jonas M, Jones CD, Kraxner F, Patwardhan A, Rogner M, Rubin E, Sharifi A, Torvanger A, Yamagata Y, Edmonds J, Yongsung C (2016) Biophysical and economic limits to negative CO2 emissions. Nat Clim Chang 6:42-50

Van Vuuren D, Bellevrat E, Kitous A, Isaac M (2010) Bio-energy use and low stabilization scenarios. Energy J $31: 192-222$

Publisher's note Springer Nature remains neutral with regard to jurisdictional claims in published maps and institutional affiliations.

\section{Affiliations}

\section{Vassilis Daioglou ${ }^{1,2} \cdot$ Steven K. Rose $^{3} \cdot$ Nico Bauer $^{4}$ - Alban Kitous ${ }^{5} \cdot$ Matteo Muratori $^{6}$. Fuminori Sano $^{7}$. Shinichiro Fujimori ${ }^{8,9} \cdot$ Matthew J. Gidden $^{10,15}$ • Etsushi Kato ${ }^{11}$ • Kimon Keramidas ${ }^{5}$. David Klein ${ }^{4}$. Florian Leblanc ${ }^{12}$ - Junichi Tsutsui ${ }^{13}$ - Marshal Wise $^{14}$. Detlef P. van Vuuren ${ }^{1,2}$}

Vassilis Daioglou

vassilis.daioglou@pbl.nl

1 PBL Netherlands Environmental Assessment Agency, PO Box 30314, 2500 GH The Hague, The Netherlands

2 Copernicus Institute of Sustainable development, Utrecht University, Princetonlaan 8a, 3584 CB Utrecht, The Netherlands

3 Energy Systems and Climate Analysis Research Group, Electric Power Research Institute, 1325 G Street NW, Suite 530, Washington, DC 20005, USA

4 Potsdam Institute for Climate Impact Research (PIK), Leibniz Association, PO Box 601203 , 14412 Potsdam, Germany

5 Joint Research Centre of the European Commission, Calle Inca Garcilaso 3, Seville 41092, Spain

6 National Renewable Energy Laboratory, Golden, CO, USA

7 Systems Analysis Group, Research Institute of Innovative Technology for the Earth, Kizugawa-shi, Kyoto 619-0292, Japan 
8 Center for Social and Environmental Systems Research, National Institute for Environmental Studies, Tsukuba, Ibaraki 305-8506, Japan

9 Department of Environmental Engineering, Kyoto University, Nishikyo-ku, Kyoto 615-8540, Japan

10 International Institute for Applied Systems Analysis (IIASA), Schlossplatz 1, 2361 Laxenburg, Austria

11 The Institute of Applied Energy, Minato, Tokyo 105-0003, Japan

12 International Research Center on the Environment and Development (CIRED), Nogent-sur-Marne, France

13 Central Research Institute of Electric Power Industry, Abiko-shi, Chiba-ken, Japan

14 Joint Global Change Research Institute, Pacific Northwest National Laboratory and the University of Maryland, College Park, MD, USA

15 Climate Analytics, Berlin, Germany 